\title{
Análisis jurídico penal sobre los tipos penales dirigidos a sancionar el feminicidio dentro de la legislación penal colombiana*
}

\author{
Criminal legal analysis on crimes aimed at sanctioning \\ feminicide within Colombian criminal legislation*
}

\section{Análise jurídica criminal sobre crimes destinados a sancionar o feminicídio na legislação penal colombiana*}

\author{
Juan David Jurado Ocampo**
}

\section{Universidad de Manizales- Colombia}

Fecha de Recibido: Enero $17 \mathrm{del} 2018$

Fecha de Aceptación: Julio 01 de 2018

Fecha de Publicación: Agosto 01 de 2018

DOI: http://dx.doi.org/10.22335/rlct.v10i4.614

* Artículo producto del proyecto de investigación denominado "feminicidio como tipo pena autónomo en la ley penal colombiana: implicaciones constitucionales, criminológicas y legales" con el cual se opta al título de Magister en Derecho, de la Universidad de Manizales. Bajo la dirección de la Doctora Carolina Valencia Mosquera.

** Abogado de la Universidad de Manizales, especialista en Investigación Criminal de la Policía Nacional de Colombia, Filiación: Asesor docente del Area Penal en el Consultorio Jurídico de Universidad de Manizales y abogado litigante. Correo electronico: juanojurado@gmail.com. Orcid: https://orcid.org/0000-0003-3044-9661

\section{Resumen}

En el presente artículo se establece un análisis de la normatividad creada para erradicar la violencia de género contra la mujer, abordando principalmente las implicaciones legales a través de la creación de conductas punibles que sancionan el delito de feminicidio; se desarrolla un paralelo entre el tipo penal de feminicidio creado con la ley 1761 de 2015 y el tipo penal anteriormente tipificado, a partir del artículo 104 numeral 11 del estatuto penal, la elaboración de este paralelo tiene como finalidad determinar en qué aspectos de la descripción típica se relacionan los dos delitos respecto a los conceptos sobre feminicidio y sobre la efectiva erradicación de la violencia de género contra la mujer en Colombia.

Palabras clave: Feminicidio, Violencia contra la mujer, Tipo penal autónomo, Tipicidad objetiva, Tipicidad subjetiva. 


\begin{abstract}
This article establishes an analysis of the regulations created to eradicate gender violence against women, mainly addressing the legal implications through the creation of punishable behaviors that sanction the crime of feminicide; a parallel is developed between the criminal type of feminicide created with the law 1761 of 2015 and the previously typified criminal type, from article 104 numeral 11 of the penal statute, the elaboration of this parallel has as purpose to determine in which aspects of the description The two crimes are related to the concepts of feminicide and the effective eradication of gender-based violence against women in Colombia.
\end{abstract}

Keywords: Feminicide, Violence against women, Autonomous criminal type, Objective typicality, Subjective typicality.

\section{Resumo}

Este artigo estabelece uma análise dos regulamentos criados para erradicar a violência de gênero contra as mulheres, abordando principalmente as implicações legais através da criação de comportamentos puníveis que sancionem o crime de feminicídio; desenvolve-se um paralelo entre o tipo penal de feminicídio criado com a lei 1761 de 2015 e o tipo penal tipificado anteriormente, do artigo 104 numeral 11 do estatuto penal, a elaboração deste paralelo tem como finalidade determinar em que aspectos da descrição Os dois crimes estão relacionados aos conceitos de feminicídio e à efetiva erradicação da violência de gênero contra as mulheres na Colômbia.

Palavras-chave: Feminicídio, Violência contra a mulher, Tipo criminal autônomo, Tipicidade objetiva, Tipicidade subjetiva.

\section{Introducción}

El órgano legislativo del estado colombiano está facultado para la creación de leyes y tipificación de delitos, de modo que el seguimiento criminológico de las leyes es reflexionado continuamente para dictaminar nuevas disposiciones sin que las medidas no vulneren principios y garantías constitucionales, la facultad a la que hace referencia esta disposición normativa ha sido denominada jurisprudencialmente con la Sentencia C-880/14, Sentencia C-496/15 Sentencia C-880/14. En ejercicio de la libre configuración legislativa como se consagra por mandato constitucional en los artículos 72 y 73 de la Constitución de 1991.

A partir del año 2015 el Congreso de la República, haciendo uso de esa libre configuración y con potestad otorgada mediante la Constitución Política para legislar en materia penal, expide la ley 1761, por medio de la cual se crea el artículo 104 A con el cual tipificar el feminicidio como delito autónomo en el Código Penal Colombiano.

La creación de la ley 1761 como disposición penal, se suma a directrices y recomendaciones internacionales como son: la Declaración Universal de Derechos Humanos (1948); la Convención Interamericana de Bogotá (1957); la Convención sobre Eliminación de toda forma de Discriminación contra la Mujer (1979); la Declaración sobre la Eliminación de la Violencia contra la Mujer (1993), y la Convención Interamericana para Prevenir, Sancionar y Erradicar la Violencia contra la Mujer ("Convención de Belem Do Pará", 1994), entre otras; a fin de que en la última década del siglo $X X$ a nivel mundial se hubiesen sumado esfuerzos conjuntos para luchar contra la violencia de género y lograr erradicarla principalmente de países latinoamericanos donde la violencia de género contra la mujer había incrementado indiscriminadamente, entre ellos Argentina, México y Chile.

El análisis de la problemática del feminicidio en un posible escenario de posconflicto, presentado por Huertas (2016) indica la influencia de actos violentos contra mujeres en países latinoamericanos siendo consecuente con la necesidad de establecer una nueva tipológica criminal en casos de abuso y violencia de género, 
determinando un escenario donde sea posible entender la problemática,

\begin{abstract}
El Instituto Nacional de Medicina Legal y Ciencias Forenses (INMLCF) reporta para el año 2014 , un total de 12.626 homicidios de los cuales 1.186 correspondieron a mujeres. Se registró como principal agresor a sujetos desconocidos en el $44,80 \%$ de los casos, como segundo agresor se encontró a la pareja o ex pareja de la víctima en el $26,95 \%$. Como dato a resaltar se encuentra que la circunstancia del hecho en el $40,48 \%$ se dio por la acción de grupos armados al margen de la ley, cuando se realizaba la clasificación con la variable violencia sociopolítica; pues se registra además que en el $80,56 \%$ el deceso se registra por violencia ejercida por parte de la pareja. Además, como principal lugar del hecho se encuentra la vía pública, calle o carretera en un $41,43 \%$ evidenciando el carácter público de muchas de las muertes. (Huertas, 2016 p. 198)
\end{abstract}

En Colombia, el delito de feminicidio ha sido tipificado a partir de la multiplicidad de circunstancias y casos en los cuales la causa de homicidio está relacionada con asuntos de género, repercutiendo en la configuración conceptual del femicidio o feminicidio, como un crimen en el que se pretende castigar con diferentes grados penales el asesinato de mujeres por el hecho de pertenecer al género femenino, pero también abarcado otras posibilidades para la comisión del delito, de modo que la idea principal de asesinar a una mujer por circunstancias de género y discriminación, se ve modificada por considerar que el feminicidio, también se puede dar por circunstancias sentimentales, laborales, entre otras.

La descripción típica, implica que cualquier asesinato que recaiga sobre una mujer, podría tomarse como feminicidio, y la persona que encuadre en este tipo penal del modo dispuesto por la ley tendrá que purgar una pena mayor a la establecida en el delito de homicidio $u$ homicidio agravado; púes el artículo 104A establece una sanción de veinte a cuarenta y un años por cometer feminicidio simple. Además, no tendrá derecho esa persona condenada por feminicidio, a acceder a los beneficios de rebaja punitiva con la misma posibilidad que si lo tienen los sujetos activos que cometen otro tipo de conductas punibles.

En tal caso es pertinente analizar cuáles pueden ser las implicaciones legales de la tipificación del feminicidio como tipo penal autónomo dentro de la ley penal colombiana, pues si se hace un análisis detallado de la nueva norma, podría llegarse a determinar que el Congreso aparentemente en algunos apartes de la misma transgredió los límites que la Constitución y su facultad de libre configuración legislativa. en consecuencia al momento de crear un tipo penal autónomo para el asesinato de mujeres, se requiere establecer diferentes quantums punitivos en las sanciones penales para los delitos de homicidio y feminicidio, dejando a un lado los principios de legalidad $y$ proporcionalidad, el primero, porque existía una norma que protegía el mismo bien jurídico denominada regida por la Ley 1257 de 2008; y el segundo, porque quienes encuadren en este tipo penal no tendrán el mismo acceso a los beneficios de la justicia premial, como lo describe Manco (2012) "se encuentra que el concepto de justicia premial refiere una idea consistente en hacer uso de premios y castigos con diversos fines, entre los cuales se encuentran los de estimular la confesión, delación y terminación anticipada del proceso". .

Las implicaciones legales, hacen referencia a la posible vulneración del principio de tipicidad, como se demarca en la Sentencia C-827 de 2011:

Así, la tipicidad como principio se manifiesta en la "(...) exigencia de descripción específica y precisa por la norma creadora de las infracciones y de las sanciones, de las conductas que pueden ser sancionadas y del contenido material de las sanciones que puede imponerse por la comisión de cada conducta, así como la correlación entre unas y otras (p. 20)

Lo anterior se desprende del principio de legalidad, como se indica en la misma disposición 
jurisprudencial desde las tres dimensiones en las que se propende por reserva de ley en sentido material, ya que el surgimiento de tipos penales compete al legislador; una definición de la conducta punible y las sanción de manera clara, precisa e inequívoca; y la irretroactividad de las leyes penales, salvo su aplicación favorable.

Las implicaciones legales aluden a criterios que deben ser considerados dentro de la legislación penal preexistente en Colombia, antecediendo la ley 1761 , le suplía una tipificación que sancionaba las muertes de mujeres por el hecho de pertenecer a su género, es decir, ya había una referencia normativa dentro del código penal respecto al feminicidio; a partir el año 2008 el artículo 104, refiriendo los agravantes del homicidio, integró el numeral 11, en el cual se menciona que durante el acto cometido contra mujer por el hecho de ser mujer, de modo que ya existía una herramienta penal dirigida a erradicar la discriminación contra la mujer por el hecho de ser tal.

Por lo anterior, dentro de la presente investigación se da desarrollo, al análisis comparativo entre una y otra norma, aplicando los elementos de la dogmática jurídico penal, para determinar cuáles son los alcances penales de cada una, y lograr determinar las implicaciones que se han generado a raíz de la creación del delito de feminicidio como tipo penal autónomo dentro de la ley penal colombiana.

\section{Método}

La investigación jurídica desarrollada para obtención de este producto académico, ha seguido el procedimiento indicado por el método cualitativo, siguiendo los lineamientos del enfoque histórico hermenéutico, con un énfasis de tipo explicativo y un diseño bibliográfico que acude a técnicas pero también al análisis de contenido y el análisis normativo.

El enfoque cualitativo descrito por Grinnell (1997) también llamado investigación naturalista, fenomenológica, interpretativa o etnográfica, incluye una variedad de concepciones, visiones, técnicas y estudios no cuantitativos. Para guiar diversas áreas de investigación. Sin embargo, en lugar de que la claridad sobre las preguntas de investigación e hipótesis preceda a la recolección y el análisis de los datos (como en la mayoría de los estudios cuantitativos), por su parte los estudios cualitativos pueden desarrollar preguntas e hipótesis antes, durante o después de la recolección y el análisis de los datos. Con frecuencia, estas actividades sirven, primero, para descubrir cuáles son las preguntas de investigación más importantes, y después, para refinarlas y responderlas. La acción indagatoria se mueve de manera dinámica en ambos sentidos: entre los hechos y su interpretación, y resulta un proceso más bien "circular" y no siempre la secuencia es la misma, varía de acuerdo con cada estudio en particular.

La metodología cualitativa, al no implicar de forma directa una medición numérica, establece un análisis no estadístico, la recolección de los datos resulta del interés de las interacciones entre individuos, grupos y colectividades. El investigador se cuestiona de forma abierta, sobre datos expresados a través del lenguaje escrito, verbal y no verbal, así como visual, elementos que posteriormente serán descritos y analizados a partir de las categorías que le resaltan relevancia, vinculando y reconociendo sus tendencias personales (Todd, 2005).La preocupación directa del investigador se concentra en las vivencias de los participantes tal como fueron (o son) sentidas y experimentadas como se resalta en Sherman y Webb (1988) al establecer este método para la investigación social, por su parte Patton (1980, 1990), define los datos cualitativos como descripciones detalladas de situaciones, eventos, personas, interacciones, conductas observadas y sus manifestaciones. Ahora bien, el proceso de investigación cualitativa articulado en un enfoque Histórico - Hermenéutico tiene un carácter de espiral desplegado en tres grandes fases: la descripción, la interpretación y la constitución de sentido o fase de construcción teórica. (V, 2009)

Respecto a esta última fase, la misma se materializó en este producto de investigación al 
realizar el respectivo estudio de tipicidad sobre la descripción del delito de Feminicidio consagrado en el artículo 104A y 104B de la ley 599 del 2000, ya que, de esta manera, se pudieron articular los elementos criminológicos y constitucionales que se abordaron en las primeras fases para que, finalmente, lograra generarse una construcción teórica por parte del investigador respecto a las implicaciones legales de la tipificación del ilícito bajo estudio. Por lo expuesto, esta investigación se desarrolló bajo el enfoque histórico hermenéutico, pues el problema de investigación debió ser abordado desde la creación de nuevos paradigmas y el análisis de paradigmas ya establecidos, y esto se alcanzó a través de la interpretación de textos y contextos, de tradiciones y prejuicios, que permitieron identificar nuevos caminos para proponer jurídica, social y criminológicamente, Gadamer, citado por Aucejo (2017).

Ricoeur (como se citó en $V$, 2009), tambien desarrolla un diálogo concordante con Gadamer () para quien la investigación hermenéutica, centrándola en el examen y valoración de la riqueza del lenguaje y de los símbolos, así como en un diálogo con las disciplinas lingüísticas, con el análisis lingüístico y con la crítica de las ideologías habermasiana. Ricoeur (s.f) está de acuerdo con Aucejo (2017) en dar importancia al "acontecimiento de la tradición", pero considera que no por ello la hermenéutica debe silenciarse frente a la demanda de la crítica de las ideologías.

El tipo de estudio exploratorio, según Sampieri (2010) es definido como:

Los estudios exploratorios se realizan cuando el objetivo es examinar un tema o problema de investigación poco estudiado, del cual se tienen muchas dudas o no se ha abordado antes. Es decir, cuando la revisión de la literatura reveló que tan sólo hay guías no investigadas e ideas vagamente relacionadas con el problema de estudio, o bien, si deseamos indagar sobre temas y áreas desde nuevas perspectivas. (Sampieri, 2010 p. 79)
Por la fundamentación teórica precitada, y la relación de la definición del autor con el problema de investigación aquí desarrollado. se pretende que el alcance de la investigación sea de carácter exploratorio, toda vez que, se espera examinar un problema de investigación que no ha sido estudiado lo suficiente, puesto que, al realizar el rastreo de literatura sobre el asunto a investigar, se encontró que respecto al tema hay información referente a la conceptualización del delito y la clasificación del mismo; no se encontraron investigaciones que desarrollaran un análisis de las implicaciones de la creación y aplicación del delito, relacionando este con parámetros de constitucionalidad, principialística y elementos de la criminología.

\section{Resultados}

De forma introductoria se presenta a continuación un abordaje desde las diferentes fuentes y referentes conceptuales, que dan lugar al análisis comparativo de feminicidio, de modo que los autores referidos fundamentan cada una de las categorías que delimitan los objetivos propuestos en medio de la investigación para la obtención de resultados.

En consecuencia, el feminicidio como tema principal desarrollado en esta investigación, implica relaciones directas entre criterios normativos y la discusión de género, sin embargo, el abordaje de este tema desde plantea referencia a los diferentes elementos teóricos que complementan el término feminicidio, una vez que se debe observar la investigación desde el planteamiento del problema y la pregunta de investigación, los cuales, pretenden estudiar las implicaciones constitucionales, criminológicas y legales de la creación del feminicidio como tipo penal autónomo en la ley penal colombiana.

Por lo anterior, se resalta desde lo criminológico, poder comprender como se generó el termino feminicidio y como se convirtió en conducta punible, posteriormente, se identifican, ¿cuáles son los principios dentro del derecho penal que deben tenerse en cuenta para el desarrollo del estudio sobre la creación del feminicidio como tipo penal autónomo? Desde la identificación 
anterior, de modo que dé lugar al estudio desde la dogmática penal y el principio de legalidad, sobre las protecciones penales a la violencia de género.

Las siguientes subcategorías de análisis se disponen teóricamente a partir del origen término feminicidio y su implementación dentro los discursos sobre erradicación de la violencia de género contra la mujer.

\section{Surgimiento del concepto de feminicidio}

Esta categoría teóricamente, se instaura en deferentes s momentos históricos en el cuales el papel de la mujer en la sociedad permitieron pensar en el término feminicidio, de modo que su uso si bien está contenido en la historia universal donde la posición de la mujer se ha visto reducida, las posturas teóricas desde el siglo XX se convierten en referentes dando lugar a la palabra feminicidio dentro de los discursos sociales y jurídicos.

Desde la cultura griega, aproximadamente entre los años 427 - 327 aC, Platón sostenía que las mujeres eran el resultado de una degeneración física del ser humano (como se citó en Censori, 2014), entrada la edad media, se ampliaron algunas prerrogativas para las mujeres, quienes ya podían tener y administrar feudos, ir a cruzadas, gobernar, dirigir monasterios y abadías, llegando algunas de ellas a adquirir gran poder político, económico y social, ya fuera por sus tierras, cargo, parentesco o actividad. Sin embargo, Censori (2014), refiere que para esta época comenzaron a verse múltiples actos de violencia contra la mujer.

Del mismo modo durante la edad moderna y contemporánea, la posición de la mujer en la sociedad se veía condicionada al supremacía del género masculino, no obstante este periodo de tiempo evidencio grandes cambios económicos, políticos, científicos y económicos, al parecer estos cambios no modificaron la condición de la mujer dentro de la sociedad. En la revolución francesa los principios de igualdad, libertad y fraternidad, si bien se implementaron como derechos fundamentales, estos eran aplicables para quienes hicieran parte de ese grupo social que lideró la revolución, lo que implicaba, que tanto pobres, esclavos y mujeres, seguían viviendo bajo las mismas circunstancias de inferioridad frente al resto del conglomerado; a lo anterior se suman los hechos que tuvieron lugar durante la revolución industrial, como indica Fernández (2006) para quien esta época logró un desplazamiento del campo a la ciudad y generar mayores oportunidades de empleo para los hombres por la cantidad de nuevas posibilidades que se crearon con la aparición de los avances tecnológicos.

entrado el siglo $\mathrm{XX}$, siguiendo la de Censori (2014) aparecen movimientos promovidos por las mujeres como protesta social a la degradación histórica que habían sufrido tanto por el hombre, como por las instituciones estatales que había todo el tiempo constituido estructuras de poder público donde las mujeres eran excluidas de la esfera. Es en este contexto de subordinación de la mujer se emancipa el feminismo, como un movimiento social y político, preocupado por lograr la igualdad de las mujeres, pero también por la equidad del género. a causa de este movimiento las mujeres obtuvieron importantes concesiones, tanto en el campo de los derechos políticos, como con los derechos humanos, civiles y sociales, logrando incluso reconocimiento en los discursos jurídicos y en el campo de la criminología. (Censori, 2014, p. 7)

Sin embargo, a principios de los años setenta del siglo XX, apareció la Tesis de la Liberación, la cual, según Moreno (2009) se preguntaba ¿por qué los hombres delinquían más que las mujeres? y si ello se debía a diferencias esenciales habidas entre los sexos, o si podía disminuir la delincuencia en los hombres con el cambio de las circunstancias. Esta idea de la liberación, consiguió crear un movimiento feminista liberal, el cual se desarrolló como movimiento feminista jurídico en sus inicios desde finales del siglo XIX y llegaría a su punto más alto de reconocimiento a finales de la década de los sesenta alcanzando finalmente en este momento histórico que el derecho trata al sexo femenino de manera compleja y se constituye en un instrumento de 
reforma social y una fuerza que contribuye a mantener a las mujeres en su sitio, el cual han ocupado debido al desplazamiento machista a través de la imposición de normas jurídicas que le impiden a la mujer ser parte activa dentro de la sociedad (Censori, 2014)

Finalmente, el termino feminicidio, que ya había sido abordado como un concepto relacionado con la criminología y el derecho penal, antecede directamente de la voz inglesa femicide, utilizada por primera vez por Diana Russel en el Tribunal Internacional sobre Crímenes contra las Mujeres, celebrado en Bruselas, en 1976, y más tarde, en la publicación "Speaking the Unspeakable" de Caputi y Russel (1990) texto que posteriormente formaría parte del libro "Femicide: The Politics of Woman Killing", publicado por Russel y Radford (1992).

Posterior a la aparición del concepto feminicidio, se abre la discusión teórica entre autores como Russel (1992) y Vásquez (2008), en contraposición a la postura de Lagarde (1996) y Monárrez (2000). Diferencias conceptuales que serían dirimidas por Vásquez (2008) al afirmar que Caputi y Russel (1990) emiten un concepto restringido sobre feminicidio, y termina apoyando la postura de Lagarde (1997).

\section{Principios constitucionales}

Respecto al principio y derecho a la igualdad, es prudente resaltar que al tratarse de un principio de ley integrado en la declaración universal de los derechos humanos del 10 de diciembre de 1948 , en el cual se indica que los seres humanos nacen libres e iguales en dignidad y derechos. Adicional a esto, nuestra constitución consagra este principio en su preámbulo, y lo materializa como derecho en el artículo 13 de la carta constitucional de 1991, asimismo reconocida en el código penal colombiano en su artículo 7 . Si bien la fundamentación normativa dispuesta anteriormente permite integrar el concepto al sistema penal colombiano, también este concepto da lugar a profundizar en la comprensión de un contexto tendiente a la igualdad, en tanto que las posturas frente a este principio indican que debe analizarse desde un sentido formal y material. En precisando en ello que igualdad en sentido formal se enfoque en garantizar el principio de legalidad y promueve la seguridad jurídica, de modo que el principio de igualdad se materializa principalmente en la igualdad ante la ley.

Desde el punto de vista del legislador, el principio de igualdad formal determina que el creador de la ley no puede crear disposiciones estableciendo en ellas disposiciones basadas en criterios prohibidos constitucionalmente, como son la raza, la religión, el sexo, entre otros; como se evidencia mediante la tipificación del feminicidio como tipo penal autónomo, teniendo en cuenta la diferenciación en la tipicidad y en la sanción a imponer que contiene este tipo penal. Contrario sensu, la igualdad material, lo que pretende, es satisfacer necesidades fundamentales de la persona, lo que le impone al Estado la obligación de procurar por que aquellas personas que se encuentren en situaciones reales de desigualdad (condiciones económicas, sociales, culturales) sean prioritariamente favorecidas con los beneficios que el Estado le pueda otorgar.

La Corte Constitucional en sentencia C- 530 de 1993, en relación con las modalidades de la igualdad, aplicando los diferentes sentidos formal y material, integra la postura de la Corte, en la cual debe analizarse la aplicación del principio de igualdad al ámbito jurídico penal, por tal motivo debe entenderse que el concepto de igualdad formal es el fundamento de la antijuridicidad en sentido formal, toda vez que la antijuridicidad en este sentido va dirigido a todo tipo de persona que comete una conducta que efectivamente está en contra del ordenamiento jurídico penal, en un tratamiento igual ante la ley, y para todos. Contrario a lo citado, la igualdad en sentido material, unida a los principios de dignidad y libertad se constituye para conformar el principio de la culpabilidad, promoviendo la máxima de tratamiento igual para los desiguales. De este modo, la igualdad material, al ser el soporte del principio de culpabilidad, lo es también de los fines de la pena, sobre todo del fin preventivo especial de la sanción.

En consecuencia con el principio de igualdad, a la par con el principio de legalidad, dan lugar al 
principio de determinación, y se constituyen en una limitación al poder normativo del Estado, que se traduce en la imposibilidad del legislador para crear leyes que no tengan carácter general y que no realicen una definición abstracta de la conducta prohibida. (Sánchez, 2014). La creación de normas penales por parte del legislativo va secundado por el análisis de ponderación de principios para evitar posibles vulneraciones a garantías constitucionales, en este sentido el principio de la igualdad contenido en ambos sentidos tanto formal como material, de forma paralela las relaciones existentes con el principio de legalidad en la configuración del principio de determinación. Sin embargo, se hace relevante referir el principio de razonabilidad.

La razonabilidad como principio, encuentra sus cimientos en la ponderación de los valores constitucionales y no simplemente en la confrontación lógica de los mismos, tal y como lo indica la Corte Constitucional en sentencia C-022 de 1996, M.P, Carlos Gaviria Díaz, por tal motivo, el juicio de razonabilidad se dirige por una metodología específica, que como indica la Corte, agota distintas etapas del proceso de análisis razonable: primero debe analizarse el fin que busca la medida, en segundo lugar, analizar el medio que se pretende emplear, para finalmente, analizar de manera razonable, la relación que existe entre el fin y el medio.

En consecuencia, desde el principio de razonabilidad, se indica la clasificación que la Corte Constitucional establece en la sentencia C287 de 2012, M.P María Victoria Calle, respecto a ¿cuáles son los tipos de juicio de razonabilidad que se presentan? basado en las tres etapas que deben contener los juicios de razonabilidad en la metodología que se aplique; cuando la aplicación del juicio es leve, es suficiente con establecer que el fin propuesto y el medio establecido por la norma se ajustan a la constitución (son legítimos) y que el medio escogido por el legislador es apto para lograr el fin propuesto. También ha indicado que el juicio intermedio es más exigente, por cuanto en este caso debe corroborarse que la medida, además de ser legítima y apta, es efectivamente conducente para lograr el fin propuesto.
La referencia establecida por la Corte sistemáticamente al principio de proporcionalidad, indica que en el desarrollo de este objetivo específico, se aborde ese principio, pues aunque va vislumbrándose la igualdad (que debe aplicarse en la creación de normas penales) en sentido formal, y que el juicio de razonabilidad (aplicado en sentido estricto) para determinar la proporcionalidad como se enmarca al momento de hacer el análisis de constitucionalidad del feminicidio como tipo penal autónomo en la legislación penal colombiana.

En términos de la corte suprema de justicia, sentencia C-799 de 2003, el juicio de proporcionalidad es:

Una herramienta argumentativa que
incorpora exigencias básicas de
racionabilidad medios-fines, así como
una exigencia de justificación de la
actividad estatal cuando restringe los
derechos fundamentales de las personas.
En el mismo sentido, la proporcionalidad,
es un criterio de interpretación
constitucional que pretende impedir los
excesos o defectos en el ejercicio del
poder público, como una forma
específica de protección o de realización
de los derechos y libertades individuales.

Es en este punto, donde debe entenderse el principio de proporcionalidad como derivación del principio de igualdad y razonabilidad en el campo penal, y comienzan a interrelacionarse los principios aquí expuestos. El motivo de esta derivación se da por el hecho de constituirse en fundamento de los principios penales de exclusiva protección de bienes jurídicos como finalidad del derecho penal y del derecho penal fragmentario, del principio de responsabilidad personal y principalmente, de la categoría dogmática de la culpabilidad.

En conclusión, frente al estudio de estos principios al momento de crear el feminicidio como tipo penal autónomo en la ley penal colombiana, debe tenerse en cuenta que: el principio de igualdad debe ser abordado desde 
su sentido formal, es decir, igualdad ante la ley; el principio de razonabilidad debe ser abordado desde el juicio estricto que hace parte de la misma; y el principio de proporcionalidad, debe analizarse desde el control estricto que realiza el órgano constitucional.

\section{Análisis de tipicidad de los delitos de homicidio agravado y feminicidio}

Para elaborar el respectivo análisis sobre los tipos penales anteriormente expuestos, se abordará la teoría finalista del derecho penal, la cual fue estructurada principalmente por el teórico de la corriente dogmática Hans Welzel (1970), esta teoría sostiene que el tipo penal siempre tiene un aspecto subjetivo, y no solo a veces como lo sostenía la escuela neoclásica, así mismo el autor propone con relación a la culpabilidad, que su esencia no radica en el nexo psicológico, dolo, sino en un puro juicio de reproche (Roda 1963).

Sobre la tipicidad, el finalismo sostiene que es el primer elemento que debe tenerse en cuenta para analizar si un sujeto efectivamente podrá ser declarado penalmente. Por tanto, la tipicidad es un elemento relacionado con el principio de legalidad, es decir, que esta primera fase de análisis del tipo, va dirigida a encuadrar la conducta desplegada en la descripción legal, típica y objetivamente consagrada en la ley, a este proceso se le denomina juicio de acomodación típica, donde se estudian los elementos objetivos y subjetivos del tipo penal, tales como el verbo rectos, el sujeto activo, el sujeto pasivo, el bien jurídico tutelado y los elementos normativos, y se adiciona a este análisis lo referente a la tipicidad subjetiva, la cual se encarga de determinar la modalidad en la cual se comete la conducta, ya sea dolosa, culposa o preterintencional. Welzel (1970), no trasladó el dolo de la culpabilidad a la acción típica como suele mencionarse normalmente, sino que lo dejó donde lo encontró, el dolo como voluntad hace parte de la acción por que la voluntad es la espina dorsal de ella, y si en el acto del conocimiento no se puede variar el objeto del conocimiento, hay que dejarlo en la acción que es su lugar natural según la psicología.
Por lo anterior, se considerar la ubicación del dolo en la tipicidad y no en la culpabilidad, pues quiere decir que en casos de feminicidio, el dolo debe configurarse desde el inicio de la ejecución y consumación de la conducta punible, teniendo en cuenta la intención efectiva del sujeto activo de cometer asesinato contra una mujer por el hecho de ser mujer y no motivado por otros móviles como el perfeccionamiento de otra conducta punible.

Contrario a ello, si el dolo siguiera ubicándose en la culpabilidad se estaría presumiendo por el legislador, que el hecho de solo constituirse en el elemento típico per se estaría encuadrando en los otros dos elementos, y la culpabilidad estaría confundiendo su finalidad de analizar los elementos psicológicos del autor, confundiendo el dolo que es la voluntad y el conocimiento, con los elementos psicológicos que son la capacidad de autodeterminación.

\section{Discusión}

En Colombia la tipificación del delito de feminicidio se implementó desde el año 2008, cuando a través de la ley 1257 se dictan normas de sensibilización, prevención y sanción de formas de violencia y discriminación contra las mujeres, por medio de la ley que se agregó un numeral al artículo 104 del código penal, el cual indica las modalidades de agravación del delito de homicidio. En el Artículo 26 como modificación al numeral 1 y la adición del numeral 11 de la Ley 599 de 2000 se logra que si se cometiere contra una mujer por el hecho de ser mujer el agravante_pese a la existencia de esta nueva regulación, durante siete años de vigencia de la tipificación, la aplicación del ambos casos donde se cometía un homicidio contra una mujer era difícil de realizar, toda vez, que debían existir elementos probatorios suficientes para determinar que el autor del delito cometió el ilícito contra una mujer, por el hecho de ella pertenecer al género femenino; como se explicará en el desarrollo de este acápite; y no por otros motivos como los problemas sentimentales de pareja o cuestiones pasionales. 
Por tal razón la imposibilidad de aplicación del agravante del homicidio, y por los argumentos respecto a la posición histórica de la mujer dentro de una sociedad, como lo indica Censori (2014)

Como consecuencia de la subordinación de la mujer respecto al hombre, que prevaleció durante el siglo XIX dando lugar al feminismo, como movimiento social y político, preocupado por lograr la igualdad de las mujeres, por la equidad del género, logrando una serie de derechos para ellas de los que antes carecían, firmándose incluso convenciones internacionales para tal fin la Declaración Universal de Derechos Humanos (1948), la Convención Interamericana de Bogotá (1957), la Convención sobre Eliminación de toda forma de Discriminación contra la Mujer" (1979), la Declaración sobre la Eliminación de la Violencia contra la Mujer (1993) y la Convención Interamericana para Prevenir, Sancionar y Erradicar la Violencia contra la Mujer (Convención de Belem Do Pará, 1994; D'Gregorio, 2011).

considerando los casos emblemáticos de asesinatos contra mujeres como el de la señora Rosa Elvira Cely en el año 2012, quien fue asesinada por un compañero de estudio, después de ser accedida carnalmente; y debido al incremento en las denuncias sobre violencia contra la mujer en diferentes estadios sociales; en el año 2015, el Congreso de la República promulgó la ley 1761, por la cual se creó el tipo penal de feminicidio como delito autónomo, denominada también la ley "Rosa Elvira Cely", debido al asesinato que se cometió en contra de esta mujer en el año 2012 y el cual llamó la atención de las autoridades, del gobierno y conto con una gran cobertura mediática, se determina la ley 1761 en su artículo 2 y la Ley 599 de 2000 tendrá un artículo 104A dictaminó feminicidio a quien causare la muerte a una mujer, por su condición de ser mujer o por motivos de su identidad de género o en donde haya concurrido - antecedido cualquiera de las siguientes circunstancias, incurrirá en prisión de doscientos cincuenta a quinientos meses.

Con lo anterior el análisis de la tipicidad objetiva y subjetiva de cada uno de los tipos penales creados hasta el momento en Colombia para proteger a las mujeres de los actos de violencia de género, principalmente el que se materializa a través del asesinato de las mujeres por su condición de ser mujeres.

\section{Tipicidad objetiva}

Se considera este criterio a partir de La teoría de la acción finalista propuesta por Hans Welzel (), en primera instancia, y para dar un orden al análisis objetivo del delito, considerando el concepto de bien jurídico, que pretende protegerse con la penalización de esta conducta, tanto con la tipificación del agravante del artículo 104 como con la penalización del feminicidio considerado como tipo penal autónomo en los artículos $104 \mathrm{~A}$ y $104 \mathrm{~B}$, desarrollando así un estudio basado en un razonamiento deductivo, donde se comenzará por entender por qué la política criminal propone esta conducta como penalizarle, y finalizando con la comprensión de cada elemento que estructura la descripción típica del ilícito.

El homicidio agravado por el numeral 11, integrado en el libro segundo, título primero de la ley 599, consagra el feminicidio, con salvedad de la protección de la vida y la integridad personal, y en delitos como los anteriormente descritos, también abarcando la protección a la igualdad de género. Todos estos derechos considerados como derechos fundamentales según la constitución política de 1991 en sus artículos 2, 11, 13, 93 y 94. Fundamento constitucional que se adhiere a los tratados internacionales ratificados por Colombia, como son Ley 248 (1995, diciembre 29) (Yáñez y Castellanos, 2016). Por medio de la cual se aprueba la Convención Internacional para prevenir, sancionar y erradicar la violencia contra la mujer. Ley 984 (2005, agosto 12). Por medio de la cual se aprueba el "Protocolo facultativo de la Convención sobre la eliminación de todas las formas de discriminación contra la mujer", adoptado por la Asamblea General de las Naciones Unidas el seis (6) de octubre de mil novecientos noventa y nueve (1999); los cuales 
van dirigidos a la protección, sanción y erradicación de cualquier tipo de violencia contra la mujer. El Estado tiene la obligación de generar blindajes y protecciones especiales, tal y como lo indican los artículos de la carta política.

En conclusión, que el objeto material del delito en sentido estricto se trata de la vida de la mujer o la persona identificada como mujer como lo señala la exposición de motivos de la ley, este es un tipo pluriofensivo (se lesionan o ponen en peligro varios bienes jurídicos), a saber: la vida, la integridad personal, la dignidad humana, la igualdad, la no discriminación y el libre desarrollo de la personalidad.

Expuesto lo anterior, y deteniendo el análisis en los bienes jurídicos que se protegen con la penalización del feminicidio a través del agravante o del tipo penal autónomo, ahora es menester adentrarse en el delito como tal y en todas sus especificaciones, cada uno de los elementos que en conjunto dan como resultado la descripción típica. De acuerdo a lo indicado en los principios constitucionales, se presentan: el verbo rector, el sujeto activo, el sujeto pasivo y los elementos normativos.

El verbo rector, al ser el eje central dentro de la descripción de cualquier delito, ya que a partir del establecimiento de una conducta como verbo rector de un ilícito, se comienza a crear un tipo penal especial y único, que debe ser claro para que la acomodación de la descripción típica concuerde fácilmente con las acciones y conductas humanas desplegadas en el trasegar cotidiano de una sociedad. Sobre el concepto de verbo rector, Velázquez (2017), explica que:

Como los tipos penales describen conductas humanas, es apenas normal, que en todos ellos aparezca este elemento, con mayor razón si se trata de un derecho penal de acto. El tipo doloso de la comisión describe acciones en sentido estricto, para lo que suele valer de una inflexión legal, de un verbo encargado de regir la acción o verbo rector, que es concreción de una prohibición. (Velázquez, 2017; p. 357)
En este caso específico, tanto el homicidio como el feminicidio establecen como verbo rector la conducta o acción de matar; en el delito de homicidio no está rodeado de otras descripciones adicionales del tipo, simplemente indica que el que incurra en la conducta de matar a otro incurrirá en la pena establecida. Sin embargo, al analizar el verbo rector matar en el delito de feminicidio, si se encuentra que la acción está acompañada por otros componentes que la dogmática jurídico penal denomina elementos normativos y elementos subjetivos diferentes al dolo. Es decir, que la descripción del tipo indica que lo que debe realizar el sujeto activo de la conducta es causar la muerte a una mujer; debe entenderse entonces que ya hay una especificidad en el sujeto pasivo, y además, indica que las razones para causar la muerte no serán únicamente la condición de ser mujer, sino que se sumarán a esta las razones de identidad de género y sucesos de violencia que hayan antecedido al acto o acción final de causar la muerte.

Así que las tipificaciones distintas en ambos delitos respecto al ámbito de aplicación de la descripción típica tienen mucho que ver con las variaciones del concepto de feminicidio a nivel global. Esta afirmación es adecuada teniendo en cuenta que la definición de feminicidio ha tenido dos dimensiones respecto a los bienes jurídicos que debe proteger y las acciones con las cuales debe extenderse en la aplicación para la erradicación de la violencia de género, consecuente con el concepto feminicidio generado en la discusión teórica entre autores como Russel (1998) y Caputi (1998), quienes inicialmente utilizaron el término de femicidio, dirigido a definir los asesinatos de mujeres por el hecho de ser mujeres o por circunstancias netamente de género. Mientras que otros teóricos como Lagarde (1997) y Monárrez (2000), prefieren el termino feminicidio, por abarcar más allá de la simple feminización del termino homicidio. Así lo refiere Censori (2014), al citar las últimas dos teóricas, en efecto, para Marcela Legarde (2014),

La expresión femicidio es inadecuada porque únicamente constituye una 
feminización de la palabra homicidio". Agregando Julia Monárrez que "la raíz latina que debe usarse es fémina", mientras que Ana Carcedo sostiene que "la expresión feminicidio es simplemente el homicidio de mujeres y que femicidio es la palabra utilizada por el movimiento de mujeres en Latinoamérica con contenido político y posicionamiento en la región, el cual va más allá de los casos en que existe impunidad sobre las muertes de mujeres. (Censori, 2014, p. 11)

Teniendo en cuenta lo precitado, podríamos relacionar el concepto emitido por Russel ( ), como el que va dirigido únicamente a la protección de la mujer por el hecho de ser mujer, y este concepto en Colombia fue aplicado y tipificado penalmente a través de la creación del numeral 11 como agravante del homicidio. Contrario sensu, el concepto referido por Ampuero ( 2012 ), tiene mucha más relación con la concepción actual sobre el feminicidio, es decir, que se observa al delito como una norma protectora con la función de erradicación de cualquier tipo de violencia contra la mujer.

Sobre el punto anterior, Vásquez (2008), dirime la discusión teórica y afirma que Russel (s.f) y Caputi (s.f.), emiten un concepto restringido sobre feminicidio, y termina apoyando la postura de Lagarde (1997), pues determina que actualmente las investigaciones sobre ese tipo de delitos han indicado que las instituciones, la sociedad y el Estado, deben ser partes responsables dentro de la comisión de delitos contra las mujeres:

Así es como Lagarde (1996), que las definiciones más frecuentes de femicidio y feminicidio se restringen a las muertes violentas de mujeres, consecuencia directa de delitos, excluyendo los decesos que se producen como consecuencia de leyes 0 prácticas discriminatorias -abortos clandestinos y deficiente atención de la salud de las mujeres, entre otros-. (Censori, 2014, p. 11) el concepto actual de feminicidio determina la creación del tipo penal autónomo en la legislación penal colombiana, y además, el que direcciona al legislador para que tengan en cuenta tantos elementos normativos que acompañan la acción o verbo rector.

A diferencia de la regulación anterior donde el agravante se limitaba a indicar que se sancionaría la muerte de una mujer por el hecho de ser mujer, el feminicidio como lo concibe el artículo $104 \mathrm{~A}$ de la ley 599, se protege la misma circunstancia de género pero se adicionan nuevos elementos como el de causarle la muerte a una mujer en un contexto donde haya concurrido o antecedido cualquiera de las siguientes circunstancias, tener o haber tenido una relación familiar, íntima o de convivencia con la víctima, ejercer sobre el cuerpo y la vida de la mujer actos de instrumentalización de género o sexual (Vergel, Martínez, Zafra, 2016, cometer el delito en aprovechamiento de las relaciones de poder ejercidas sobre la mujer, expresado en la jerarquización personal, económica, sexual, militar, política o sociocultural, entre otras modalidades ya referidas anteriormente.

Si bien son diversas las circunstancias sobre las cuales recae la acomodación típica del feminicidio, incluso algunos profesionales del derecho han analizado profundamente este delito y han tomado determinaciones como demandar la constitucionalidad ${ }^{1}$ del mismo por considerar que esta nueva conducta punible vulnera principios y derechos constitucionales. Pero ese asunto se abordará en otra oportunidad.

El estudio sobre los elementos objetivos de la conducta punible, han de dirigirse a los sujetos activo y pasivo que intervienen al momento de configurarse el delito, estos conceptos son definidos por Velázquez (2017). Respecto al sujeto activo:
Colombia, Corte Constitucional de Colombia. (2016). Sentencia C-297/16 Demanda de inconstitucionalidad contra el literal e) del artículo $2^{\circ}$ (parcial) de la Ley 1761 de 2015 "Por la cual se crea el tipo penal de feminicidio como delito autónomo y se dictan otras disposiciones" (Rosa Elvira Cely). Magistrado Ponente: Gloria Stella Ortiz Delgado. Bogotá, D.C. 
Cuando se enseñan los componentes exteriores del comportamiento objeto de prohibición, se debe comenzar por el sujeto activo, sujeto agente, el autor o el actor. La equiparación entre sujeto activo y autor, es, sin embargo, criticada por quienes aducen que la calidad de autor supone la responsabilidad penal, mientras que el sujeto activo no; esto es, por la persona que lleva a cabo la conducta tipificada en la ley; por regla general, las prohibiciones jurídico penales se dirigen de manera indistinta a todos los ciudadanos, sin ninguna diferencia, como se desprende de la locución utilizada por la ley: "el que, aunque algunas veces se emplean otras como "quien", "el responsable" (Velázquez, 2017, p. 354)

Esta definición aplicada a los delitos bajo estudio, nos indica que el sujeto activo de la conducta de homicidio agravado y de feminicidio, son en este caso concreto quienes perpetran el hecho delictivo de matar o causar la muerte a una mujer. Si profundizamos en que otra exigencia hace el tipo al sujeto activo, encontramos que respecto al homicidio agravado no hay ninguna especificación. Sin embargo, cuando estudiamos el feminicidio, inicialmente pareciese que no se hicieren exigencias al sujeto activo respecto a que este deba ostentar una calidad especifica; pero cuando analizamos los numerales del artículo 104 $A$, si encontramos que respecto a esos numerales si se determinan calidades específicas como la de tener o haber tenido una relación familiar, íntima o de convivencia con la víctima, de amistad, de compañerismo o de trabajo o ser perpetrador de un ciclo de violencia física, sexual, psicológica o patrimonial que antecedió el crimen contra ella.

De otro modo al analizar la calidad se le exige al sujeto pasivo de la conducta, es decir, sobre quien recae la acción delictiva, Velázquez (2017) indica que:

El sujeto pasivo del delito, esto es, el titular del bien jurídico protegido en cada caso concreto y que puede resultar o no perjudicado con la conducta del sujeto activo. Sujeto pasivo puede ser una persona física como sucede en el homicidio, o jurídica si se trata de un hurto, que también puede afectar a una persona física, o el mismo estado, si se realiza una cualquiera de las conductas previstas en los títulos XVII y XVIII de la parte especial. Incluso, puede ser el conglomerado social. (Velázquez, 2017, p. 355)

En Velázquez (2017) el sujeto pasivo lleva de nuevo aplicándolo a las conductas punibles que analizamos, refiere que en ambos delitos se exige una calidad especial al sujeto pasivo de las conductas, pues tanto en el agravante del homicidio como en la tipificación del feminicidio el sujeto activo es una mujer o una persona que se identifique en su género como tal, lo que cambia son los móviles para la comisión del delito. Por la anterior caracterización, debe entenderse que sólo con el hecho de que la víctima del asesinato sea una mujer; aparentemente ya se estaría encuadrando la exigencia del tipo penal. Sin embargo, en el feminicidio debemos analizar los componentes adicionales a la calidad de ser mujer, como por ejemplo, ser mujer víctima de maltrato por parte de su pareja, un familiar, un amigo, o ser mujer víctima de abusos de personas que ejercen poder sobre ellas.

\section{Tipicidad subjetiva}

El estudio subjetivo sobre un tipo penal, entendido como tipicidad subjetiva en Agudelo (2010), permite determinar un esquema del delito, que versa en el análisis de las categorías dogmáticas del delito en las cuales puede enmarcarse una conducta, ya sea que la acción exija un actuar doloso, culposo o preterintencional. En este caso en concreto de la investigación, ni el homicidio agravado ni el feminicidio permiten que las conductas se desplieguen a título de culpa o preterintencional; lo que hace que por inferencia, los delitos bajo observación se materialicen exclusivamente bajo la modalidad dolosa, como la mayoría de los delitos consagrados en el código penal. 
El dolo, definido como acto punitivo, en el artículo 22, mediante los dos elementos fundamentales para que el dolo se configure incluyen inicialmente el conocimiento, es decir, la certeza de que la conducta que se va a desplegar es constitutiva de sanción penal, y posteriormente un elemento, está el volitivo, lo que se refiere a tener la voluntad de desplegar la conducta teniendo conciencia de que la misma está catalogada como delito. Al respecto, Agudelo (2010), señala que,

Teoría "estricta" del dolo. El conocimiento del injusto hace parte del dolo y debe ser actual. Falta esa conciencia de antijuridicidad cuando hay error de tipo o cuando el sujeto no es consciente de que obra injustamente, como cuando supone, sin existir realmente, que existe una causal de justificación, o de exclusión de responsabilidad, o no conocía la prohibición. (Agudelo, 2010, p. 135)

Aplicado lo anterior a los delitos de homicidio agravado y feminicidio, el dolo en ambos aplica de la misma manera. El dolo se constituye, cuando el sujeto activo de la conducta sabe que el feminicidio es un delito tipificado, y sin embargo, decide por voluntad propia, causar la muerte a una mujer por el hecho de ser mujer, por circunstancias de género o bajo las circunstancias que pudieron anteceder el asesinato y que ya fueron mencionadas con anterioridad, todas descritas dentro del tipo penal.

Por lo anterior, el dolo no puede materializarse como la simple configuración del conocimiento y la voluntad de querer incurrir en el verbo rector de matar o causar la muerte a una mujer, pues el tipo penal exige unos elementos subjetivos diferentes al dolo que deben ser tenidos en cuenta para la calificación subjetiva en la tipificación. Es decir, además del dolo para cometer la acción, deben tenerse en cuenta las circunstancias descritas dentro de los delitos creados para la protección del género femenino. De no ser así, es probable que la conducta se acomode en cualquier otro tipo de homicidio.
Al respecto, la Corte Constitucional en sentencia C-297 de 2016, asunto en el cual se decidió sobre demanda de inconstitucionalidad contra el literal e) del artículo $2^{\circ}$ (parcial) de la Ley 1761 de 2015 "por la cual se crea el tipo penal de feminicidio como delito autónomo y se dictan otras disposiciones" (Cely, 2010), señala:

La conducta corresponde a dar muerte a una mujer por el hecho de serlo, por lo tanto el verbo rector es matar a una mujer. No obstante, como lo advierte la exposición de motivos de la ley, este delito se diferencia del homicidio en el elemento subjetivo del tipo. Es decir, la conducta debe necesariamente estar motivada "por su condición de ser mujer o por motivos de su identidad de género", móvil que hace parte del tipo (dolo calificado). (Cely, 2010, p. 9)

Los elementos subjetivos deben ser entendidos en sintonía al dolo calificado, es posible que la concurrencia del delito se pueda desarrollar bajo varios postulados; pues refiere la corte que la conducta se configura cuando se causa la muerte a una mujer, "por su condición de ser mujer o por motivos de su identidad de género o cuando concurran o antecedan las siguientes circunstancias (...)". Así, siguiendo una lectura literal del aparte normativo, el conector "o" que es disyuntivo, indicaría que el verbo rector "matar a una mujer" puede ligarse con tres hipótesis que configurarían el feminicidio: i) Matarla por ser mujer; ii) matarla por su identidad de género, y iii) matarla y que concurran o antecedan las circunstancias establecidas en los literales de la norma, incluido el literal e) acusado. Dicha lectura configuraría un contrasentido, en la medida en que excluiría justamente el elemento subjetivo de la conducta que configura el feminicidio.

Sumado a la anterior tipificación del feminicidio, en la exposición de motivos del proyecto de ley 107 de 2013 del Senado para la creación de la ley 1761 de 2015, se explicó que éste nuevo delito autónomo se refiere "al tipo penal que castiga los homicidios de mujeres por el hecho de ser tales en un contexto social y cultural que las ubica en 
posiciones, roles o funciones subordinadas, contexto que favorece y las expone a múltiples formas de violencia" (p.87)

La violencia es definida en la exposición de motivos precitada reseñó el artículo $1^{\circ}$ de la Convención de Belém do Pará el cual señala que: "debe entenderse por violencia contra la mujer cualquier acción o conducta, basada en su género, que cause muerte, daño o sufrimiento físico, sexual o psicológico a la mujer, tanto en el ámbito público como en el privado". (p.) Puntalmente se afirmó que el concepto dogmático de feminicidio consiste en la supresión por conducta del autor, de la vida de una mujer (tipicidad), sin justificación jurídicamente atendible (antijuridicidad), en forma intencional o dolosa, observándose una relación de causalidad entre la conducta del agente y el resultado de muerte en la mujer.

Este tipo penal se diferencia del homicidio en las motivaciones del autor, en tanto se basa en una ideología discriminatoria fundamentada en la desvalorización de la condición humana y social de la mujer, y por tanto en imaginarios de superioridad y legitimación para ejercer sobre ellas actos de control, castigo y subordinación. (Gaceta del Congreso de la República 773 de 2013, Exposición de motivos proyecto de ley 107 de 2013 del Senado).

La última descripción del tipo en la ley 1761 pretende abarcar todas las exigencias internacionales respecto a crear mecanismos efectivos para la erradicación de la violencia contra la mujer.

Al respecto Corredor et. Al. (2013) clasifican las modalidades de feminicidio que pueden desarrollarse y las cuales deben ser protegidas en las descripciones típicas de los delitos que se creen para la eficaz erradicación de violencia de género contra la mujer distinguiendo tres tipos de feminicidios:

i) Íntimo, ii) sexual sistémico, y iii) por ocupaciones estigmatizadas. El primero corresponde al asesinato realizado por quien tuvo relaciones íntimas, familiares, de convivencia o afines con la víctima. El segundo hace alusión a un asesinato acompañado de secuestro, tortura y violación. El tercero opera sobre mujeres quienes ocupaban su tiempo en actividades desautorizadas por la sociedad (incluso por las demás mujeres), (bares, prostíbulos, clubes nocturnos... (Corredor et al, 2013, p. 90)

Si bien los criterios inclusivos de este corpus de ley implican que al legislador colombiano para la tipificación de conductas punibles se basa en los postulados de la escuela finalista de la cual se ha referenciado dentro de este documento a su principal exponente Welzel (1970) el abordaje de otros elementos dogmáticos se dará en otro escenario, la creación del feminicidio como tipo penal autónomo debe regirse con los conceptos de tipicidad objetiva y subjetiva, antijuridicidad y culpabilidad, aplicando la máxima del finalismo, la cual tiene que ver con un análisis de la esencia del ser humano Welzel (1970):

Acción humana es ejercicio de actividad final. La acción es, por eso, acontecer "final", no solamente "causal". La "finalidad" o el carácter final de la acción se basa en que el hombre, gracias a su saber causal, puede prever, dentro de ciertos límites, las consecuencias posibles de su actividad, ponerse, por tanto, fines diversos y dirigir su actividad conforme a su plan, a la consecución de estos fines. En virtud de sus saber causal previo puede dirigir los distintos actos de sus actividad de tal modo que orienten el acontecer causal exterior a un fin y así lo sobre determine finalmente. (Welzel, 1970 ${ }_{\bar{\tau}}$ p. 53 - 54)

\section{Conclusiones}

En conclusión, el legislador basado en el principio de tipicidad, el cual se desprende del principio constitucional de legalidad, describe las situaciones en las cuales comúnmente se generan atropellos contra las mujeres por su condición social, y debido a esto, ya no puede permitirse que un asesinato contra una mujer se examine 
desde la órbita de un simple homicidio pasional, para entender que el delito de feminicidio también tiene unas categorías internas, o modalidad, sobre las cuales puede ser perpetrado.

\section{Referencias}

Aucejo, E. (2016). Alternative dispute resolution (ADR) in spanish and comparative tax law. proposal for latin america and spain. [Sistemas de Resolución Alternativa de Conflictos (ADR) en derecho tributario español y comparado. Propuestas para Latinoamérica y España] Revista Derecho Del Estado, (37), 3-68. doi:10.18601/01229893.n37.01

Agudelo, N. (2010). Curso de Derecho Penal, esquemas del delito. Medellín, Colombia: Ediciones nuevo foro.

Ampuero, I. H. (2012). The judicial application of law in the civil procedural act project. [La aplicación judicial del derecho en el Proyecto de Código Procesal Civil] Revista De Derecho, 25(1), 195-223. doi:10.4067/S071809502012000100009

Bejarano, M. (2014). El feminicidio es sólo la punta del iceberg. Región y sociedad, 26 (ESPECIAL4), pp.13-44.

Caputi, J y Russell, D. (1998). Femicide. Paris: Lem

Censori, L. (2014). El delito de feminicidio y su constitucionalidad. Revista pensamiento penal. Recuperado de http://www.pensamientopenal.com.ar/articul os/delito---femicidio---su -constitucionalidad

Censori, L. (2014). El tratamiento de la mujer a lo largo de la historia y la política criminal. Recuperado de http://www.pensamiento penal. com.ar/artic ulos/delito-femicidio-suconstitucionalidad.
Congreso de la República. (2013). Exposición de motivos proyecto de ley 107 de 2013 del Senado. Bogotá: Gaceta del Congreso de la República 773 de 2013

Congreso de la República. (1995). Ley 248 Convención Internacional para prevenir, sancionar y erradicar la violencia contra la mujer. Bogotá: Printed

Congreso de la República. (2000). Ley 599 Código Penal. Bogotá, Colombia.

Congreso de la República. (2004). Ley 906 código de procedimiento penal. Bogotá, Colombia.

Congreso de la República. (2005). Ley 984 Protocolo facultativo de la Convención sobre la eliminación de todas las formas de discriminación contra la mujer. Bogotá, Colombia: Asamblea General de las Naciones Unidas.

Congreso de Colombia. (2008). Ley 1257 normas de sensibilización, prevención y sanción de formas de violencia y discriminación contra las mujeres. Bogotá, Colombia.

Congreso de Colombia. (2015). Ley 1761 tipo penal de feminicidio como delito autónomo caso Rosa Elvira Cely. Bogotá, Colombia.

Corte Constitucional de Colombia. (2016). Sentencia C-297/16, tipo penal de feminicidio como delito autónomo. Bogotá, Colombia.

Corredor, M., Mendoza, N., Rincón, C., Arenas, Y., Aguilar, E. \& Villamizar, J. (2013). El feminicidio: realidad o mentira dentro de la política pública colombiana. Dixi,15(18), pp.77-100.

D'Gregorio, R. P. (2011). Four years after the promulgation of the law on the rights of women to a life free of violence. [Cuatro años después de la promulgación de la Ley sobre el derecho de las mujeres a una vida libre de violencia] Revista De Obstetricia y Ginecologia De Venezuela, 71(2), 73-76. 
Huertas, O., Patiño, M., y Ruíz, A. (2016). Análisis de la problemática del feminicidio en un posible escenario de posconflicto. Principia luris, 12(23), pp.186-215.

Jiménez, P., y Ronderos, K. (2010). Feminicidio: Un fenómeno global. De Lima a Madrid. Bélgica: Heinrich Boll Stiftung.

Juzgado 35 Penal del Circuito con Función de Conocimiento. (2017), Sentencia de Condena por Allanamiento, Rafael Uribe Noguera 2016 - 03772, feminicidio Agravado y otros. Bogotá, Colombia.

Lagarde, M. (1992). Enemistad y sororidad: hacia una nueva cultura feminista.

Lagarde, M. (1996). La multidimensionalidad de la categoría género y del feminismo. Metodología para los estudios de género. México: Instituto de Investigaciones Económicas, Universidad Nacional Autónoma de México, pp. 48-71.

Lagarde, M. (1997). Género y femenino. Desarrollo humano y democracia. Madrid, España: Horas y Horas.

Lagarde, M. \& De los Ríos, M. (2007). Por los derechos humanos de las mujeres: la Ley General de Acceso de las Mujeres a una Vida Libre de Violencia. Revista Mexicana de Ciencias Politicas y Sociales, 49(200).

Monárrez, J. (2000). La cultura del feminicidio en Ciudad Juárez, 1993-1999. Ciudad Juarez, Mexico: Frontera Norte.

Radford, J., \& Russell, D. (1992). Femicide: The politics of woman killing. Nueva York, Estates Unidos: Twayne Pub.

Radford, J., \& Russell, D. (2002). La política del asesinato de las mujeres, Ciudad de México. Ciudad de México: Universidad Autónoma de México.

Roxin. C. (1997). Derecho Penal, Parte General, Tomo I, Fundamentos, La estructura de la
Teoría del Delito. Madrid, España: editorial Civitas, S.A.

Vásquez, P. (2008). Tipificación del Femicidio/Feminicidio: otra Vía Hacia el abandono de La neutralidad de género en el derecho penal Frente a La Violencia contra Las mujeres. Derecho, Género E Igualdad, 163.

Vásquez, P. (2009). feminicidio. Nueva York, Estados Unidos: Naciones Unidas.

Vásquez, P. (2016). Cobertura mediática del femicidio y eventuales consecuencias. Consejo Editorial, 35.

Velázquez, F. (2007). Manual de Derecho Penal parte general. Bogotá: Editorial Andrés Morales.

Vergel, M., Martínez, J. \& Zafra, S. (2016). Factores asociados al bullying en instituciones de educación superior. Revista Criminalidad, 58 (2): 197-208.

Welzel, H., Ramírez, J. \& Pérez, S. (1970). Derecho penal alemán: parte general. Chile: Editorial jurídica de Chile.

Yáñez-Meza, D. A., \& Castellanos-Castellanos, J. A. (2016). El derecho a la prueba en Colombia: Aspectos favorables y críticos de la reforma del código general del proceso en el derecho sustancial y procesal. Universitas, 65(132), 561-609. doi:10.11144/Javeriana.vj132.dpca 